\title{
Incidence of hip fracture among long-term care insurance beneficiaries with dementia: comparison of home care and institutional care services
}

\author{
Juyeong Kim¹, Young Choi ${ }^{2}$ and Eun-Cheol Park ${ }^{3,4^{*}}$
}

\begin{abstract}
Background: Hip fracture among older adults is not only a major health issue but also preventable by providing proper care, but there is a lack of studies on the association between type of long-term care (LTC) service and hip fracture. This study aimed to investigate the association between the type of LTC service and the incidence of hip fracture among older adults with dementia receiving long-term care insurance (LTCl), and to investigate how such association differs according to characteristics of beneficiaries and structural characteristic of institutional care.

Method: In this retrospective cohort study, data from 2008 to 2013 were collected from 7112 LTCl beneficiaries having benefit level 1 or 2 with dementia aged 60 years or over in the Korean elderly cohort data set. Type of LTC service was categorized into institutional or home care using the LTCI Claims Database, and the incidence of hip fracture was used as the outcome variable. A survival analysis using a time-dependent Cox regression analysis was performed to examine the association between time-varying LTC service type and hip fracture.

Results: Of the 7112 older adults, 115 (1.6\%) had hip fracture during a total of 16,540 person-years. Compared to LTC beneficiaries with home care, those with institutional care had a higher adjusted hazards ratio of incidence of hip fracture (hazards ratio $=4.33,95 \%$ confidence interval, 2.84-6.59). This association was particularly strong among beneficiaries who did not have a danger of hip fracture during the mandatory assessment for benefit eligibility, who were partially ambulatory, who were from rural areas, and females.

Conclusions: Institutional care was more likely associated with a higher incidence of hip fracture than home care. The government need to watch the institutional LTC services quality and promote improvements of the institutional care quality.
\end{abstract}

Keywords: Long-term care insurance, Hip fracture, Home care, Institutional care, Quality of care

\section{Background}

South Korea (hereafter, Korea) faces one of the fastest aging population situation in the world. Changes of social environment including lessening rates of family caregiving and lack of LTC program, made the challenges of aging population worse [1-3]. The social

\footnotetext{
* Correspondence: ecpark@yuhs.ac

${ }^{3}$ Institute of Health Services Research, Yonsei University, Seoul, Republic of Korea

${ }^{4}$ Department of Preventive Medicine \& Institute of Health Services Research, Yonsei University College of Medicine, 50 Yonsei-ro, Seodaemun-gu, Seoul 120-752, Republic of Korea

Full list of author information is available at the end of the article
}

demand to the problem of older adults care increased in Korea. For the purpose of satisfying the care needs of older people with poor health condition and larger healthcare needs, LTCI system was implemented by the Korean government starting in July $2008[4,5]$.

Since the introduction of LTCI, the Korean government received positive reactions from public due to its role of helping elderly patients and their families [6]. LTCI mainly targets people aged 65 or over and those aged under 65 with diverse geriatric or other diseases, especially dementia, Parkinson's disease, and stroke [7]. The payment for the LTCI system is consisted of

(c) The Author(s). 2019 Open Access This article is distributed under the terms of the Creative Commons Attribution 4.0 International License (http://creativecommons.org/licenses/by/4.0/), which permits unrestricted use, distribution, and reproduction in any medium, provided you give appropriate credit to the original author(s) and the source, provide a link to the Creative Commons license, and indicate if changes were made. The Creative Commons Public Domain Dedication waiver (http://creativecommons.org/publicdomain/zero/1.0/) applies to the data made available in this article, unless otherwise stated. 
National Health Insurance, government subsidies, and copayments [2]. Older people can receive LTC services with low financial burden of care, and they can choose the type of service between home care $(\mathrm{HC})$ services and institutional care (IC) under the LTCI system, and the services are predominantly delivered in the private sector. As a result of high demand of LTC services, the number of beneficiaries increased from about 310,000 in 2010 to 387,000 in 2013 [7]. As social demands for LTCI increase, the Korean government tried to increase the quantity of LTC institutions including $\mathrm{HC}$ and IC. Therefore, the quantity of LTC institutions increased [7].

At the same time, the Korean government tried to improve the LTCI coverage rate. The rate of LTCI coverage rose from $1.4 \%$ in 2008 to $7.5 \%$ in 2016 [6]. Currently, the financial expense of LTCI is projected to reach 35 , 000 billion dollars [7]. In this situation, quantity of LTC services is enough to meet demand of LTC beneficiaries, but quality of LTC services has yet not been tested. Recently, policymakers in developed countries like U.K., Australia, and Canada are trying to improve the quality of LTC service, especially laying emphasis on improvement of measurement results of LTC services quality indicators [8]. The assessment and assurance of quality of care is important to ensure responsible health care expenses and provide safe and effective LTC services [9].

Although providing higher quality care to older adults is important given the aging population, it is not known whether quality of care is dependent on type of LTC services. Previously, validated studies have suggested hip fracture as an adequate indicator for the quality of LTC services [9]. Hip fracture is considered one of the most significant public health issues among older adults. It can have devastating consequences such as pain, immobilization, functional decline, delirium, and death. A study reported that $13 \%$ of older adults with hip fracture die within 3 months, and $24 \%$ die within 12 months [10]. Especially, elderly patient with dementia are more likely to have hip fracture due to defective neuromuscular regulation, gait apraxia, and cognitive impairment [11]. Although hip fracture is a significant concern, it is possible to prevent hip fracture by a supportive care environment. Because hip fracture typically occurs from falls when older adults lose their balance during daily movement, preventing hip fracture requires careful support, including assistance with moving and supervised daily living, which in turn requires considerable monetary and human resources [12].

Therefore, this study examined whether the type of LTC service is associated with the incidence of hip fracture among older adults diagnosed with dementia rated as levels 1 or 2 in LTCI benefit coverage level, based on a nationally representative sample of older adults population in Korea [4]. This study tested two hypotheses: (i) the type of LTC services are associated with the incidence of hip fracture, and (ii) the association between the type of LTC service and the incidence of hip fracture would differ by sex, region, whether the patient had a predetermined risk of hip fracture during the mandatory assessment of benefit eligibility, and ambulatory status.

\section{Methods}

Data

This study used the Korean Elderly Cohort data set from 2008 to 2013, provided by National Health Insurance Cooperation. The data set used a nationally representative sample of Korean older adults, and included LTCI claims data as well as national-level data that the Korean government requires for the clinical assessment of all LTCI beneficiaries. It includes the benefit eligibility assessment data of all enrollees and consists of the following five main sections: sociodemographic characteristics, general health status, LTC application and final decision, LTC approval checklist (LTCAC), and preliminary and adjusted entire assessment scores (LTC approval scores [LTCAS]). It also includes LTC service provider information and health insurance claims data.

The LTCI system was established to meet the high care needs of older people with poor health. Its coverage rate in the older adult population has been reported as $5.6 \%$. Since LTC financing is limited, there is a need to confine the target population to those with high care needs of beneficiaries for maximizing the effect of LTC services and to meet the great need of LTC services. In this regard, LTC approval checklist (LTCAC) is used to distinguish those with high care need among all LTC applicants. It contains five areas a total of 69 functional assessment items including physical function (23 items, including activities of daily living [ADLs] and instrumental ADLs [IADLs]), nursing and special treatments (10 items), behavioral symptoms (16 items), cognitive function (10 items), and rehabilitation needs (10 items). The LTCAC is measured by employees from NHI. Subsequently, the Need Assessment Committee calculate the preliminary LTCAS scores for 59 items based on LTCAC (excepting IADLs) following national guidelines by using a complex, highly nonlinear formula. Finally, the committee issues a final LTCI benefit coverage level from 1 to 3 after considering individual's situations and needs of special service and a physician's opinion. Lower levels indicate bigger dependency and a higher benefit amount (Level 1: very severe, Level 2: severe, Level 3: moderate). The national LTCI assessment, which was conducted initially in 2008 to identify the number of potential beneficiaries and determine the severity of their condition, served as the baseline assessment for all beneficiaries in the data set. Specific guidelines for the assessment and documentation ensure the quality of the data set. 
A mandatory assessment for LTCI benefit eligibility is conduct every year, except for those older adults with an initial high score (>100). A team consisting of nurses or social workers from LTCI fulfills the assessments to judge the LTC needs of older adults, using first hand observations of beneficiaries and interviews with families or LTC workers. Examiners conduct assessments including based on the LTCAC manual.

\section{Study population}

The eligibility criteria for the present study were a main diagnosis of dementia and a LTCI benefit coverage level of 1 or 2 . These criteria were considered the most convincing for determining the need for LTC services. Those with benefit level of 1 or 2 have the option of choosing between $\mathrm{HC}$ and IC services. The exclusion criteria were individuals with a benefit level of 3 , receiving $\mathrm{HC}$ services only in special exceptions and not having comparable characteristics to other participants in the $\mathrm{HC}$ and IC groups [13]. Additionally, individuals diagnosed with hip fracture prior to receiving LTCI benefits were excluded. Among the 99,841 LTCI beneficiaries in July 2008, 35,421 who had an LTCI benefit coverage level of 1 or 2 were selected. Of those, 10,491 had dementia. After excluding those who did not use LTC services and those diagnosed with hip fracture before becoming LTCI beneficiaries, 7112 beneficiaries were included in the final dataset.

\section{Study variables}

\section{Type of long-term care service}

$\mathrm{HC}$ and IC were considered as LTC services in this study, excluding the special cash type. HC includes home bathing, home help, adult day and night care centers, skilled nursing services, and medical equipment rental services (e.g., in-tub bath lifts, wheelchairs, and specialty care mattresses). It enable beneficiaries to use various types of $\mathrm{HC}$ services within a monthly funding limit [14]. IC contains social and recreation therapy, 24-h nursing care, rehabilitation, and other conveniences [13].

\section{Hip fracture}

Hip fracture was defined as a record indicating a diagnosis of femoral fracture. Specifically, we retrieved all claims records for the hospital admissions of patients aged 60 years or older diagnosed with femoral fracture (based on International Classification of Diseases, Tenth Edition [ICD-10] diagnostic codes: S72). The diagnosis codes were selected based on previous studies [15].

We intended to identify the association between the incidence of hip fracture and LTC service type. Therefore, we defined the incidence of hip fracture by LTC service type as the occurrence of a diagnosis of hip fracture during the period between the start and end dates of a given LTC service.

\section{Control variables}

Socio-demographic variables included age (60-74, $\leq 80$, $\leq 85$, $\leq 90$, or $>90$ years), sex (male/ female), region (urban/rural), equivalent household income (high, middle, or low), primary caregiver (spouse, children, care assistant, or none), cohabitation (living alone, living with the spouse, family members, caregivers from long term care facilities, or others), and year. Information on socio-demographic variables was collected from corresponding section of the LTCI benefit eligibility assessment data. Health-related variables included predetermined risk of fracture on the during the mandatory assessment for benefit eligibility was conducted (yes/ no), ambulatory status (possible, partially possible, or impossible), LTCI benefit coverage level (1/ 2), Charlson Comorbidity Index (CCI; 0, 1, 2, or $\geq 3$ ) [16], LTCAS score, ADL score, cognitive function score, and behavioral symptoms score. Information on these variables were collected from the LTCAC findings in the LTCI benefit eligibility assessment data. Information about socio-demographic and health-related variables was obtained since the year prior to the commencement of LTCI services. Only the comorbidity component of the CCI was calculated, and all diagnostic information was collected from inpatient and outpatient billing data within the diagnosis year.

For structural characteristics, ownership type of LTC service providers (local government, non-profit, or private) and the number of clinic room in the IC facility (with or without a clinic room) were included. This information was collected by matching an LTC provider's ID with LTC providers' information and LTCI claim data.

\section{Statistical analysis}

Descriptive statistics were conducted for all variables as frequencies and percentages for categorical variables using the Chi-squared test. The survival probability for the incidence of hip fracture was estimated by the Kaplan-Meier product limit method with log-rank tests to stratify type of LTC services. In order to investigate the association between type of LTC services and the incidence of hip fracture, we analyzed the cumulative mean function estimate for recurrent events data using a Cox's proportional hazards model [17]. The log of cumulative hazards was proportional to the follow-up time, and no violations of the proportional hazards assumption were detected. Subgroup analyses were conducted to examine the association between type of LTC services and the incidence of hip fracture by sex, region, having a predetermined risk of fracture on the mandatory 
assessment for determining LTC benefit eligibility. Additionally, subgroup analyses were conducted to identify the association between structural characteristics (number of clinic room) of IC facilities and incidence of hip fracture among beneficiaries receiving IC as compared to those receiving $\mathrm{HC}$. All statistical analyses were performed using SAS statistical software version 9.4 (SAS Institute, Cary, NC, USA).

\section{Results}

Table 1 shows the frequencies and percentages for all variables at baseline, stratified by censored status. Of the 7112 eligible participants, 115 (1.6\%) experienced hip fracture during the study period. At baseline, $39.4 \%$ of the study population received IC, and $60.6 \%$ received $\mathrm{HC}$.

Regarding the association between the LTC service type and the incidence of hip fracture, 90 (3.2\%) of the 2802 participants who received IC experienced hip fracture during the follow-up period, compared to only 25 $(0.6 \%)$ of the 4310 participants who received HC. We observed significant differences in the incidence of hip fracture by type of care, sex, primary caregiver, cohabitant, having a predetermined risk of fracture based on the mandatory assessment for determining LTC benefit eligibility, and ambulatory status.

Figure 1 shows the result of Kaplan-Meier analysis. The mean survival time of those receiving $\mathrm{HC}$ and IC was 325.5 days and 271.3 days, respectively. The difference in survival for the incidence of hip fracture in participants was greatest at 400 days ( $p$-value $<0.0001$ by log-rank test).

Table 2 shows the result of the Cox proportional hazards regression analysis of the adjusted effect of the type of LTC service on the incidence of hip fracture. As compared to those receiving $\mathrm{HC}$, those receiving institutional care had a higher adjusted hazards ratio (HR) for hip fracture ( $\mathrm{HR}=4.23,95 \% \mathrm{CI}, 2.83-6.58)$.

Table 3 outlines the findings of the subgroup analysis according to gender, income level, region, predetermined risk of fracture on the mandatory assessment for determining LTC benefit eligibility, and ambulatory status. Among those receiving IC, the following groups all had a higher adjusted HR for hip fracture: participants who were female $(\mathrm{HR}=4.73,95 \% \mathrm{CI}, 2.96-7.53$ vs. male: $\mathrm{HR}$ $=3.54,95 \% \mathrm{CI}, 1.24-10.09)$, those residing in rural areas $(\mathrm{HR}=4.69,95 \% \mathrm{CI}, 2.60-8.44$ vs. urban areas: $\mathrm{HR}=$ $4.26,95 \% \mathrm{CI}, 2.27-7.90)$, those who did not have a predetermined risk of fracture based on the mandatory assessment for determining LTC benefit eligibility $(\mathrm{HR}=$ $5.27,95 \% \mathrm{CI}, 2.15-12.92$ vs. those who had a predetermined risk: $\mathrm{HR}=4.09,95 \% \mathrm{CI}, 2.53-6.62)$, and those who were partially ambulatory $(\mathrm{HR}=4.96,95 \% \mathrm{CI}, 2.24-$ $11.00)$ and not ambulatory ( $\mathrm{HR}=4.62,95 \% \mathrm{CI}, 2.69-$
7.97 vs. those who were ambulatory: $\mathrm{HR}=2.21,95 \% \mathrm{CI}$, 0.61-8.02).

Table 4 outlines the findings of the subgroup analysis of the association between structural characteristics of the institution and incidence of hip fracture as compared with beneficiaries with HC. As compared to those received HC, participants who received IC without a clinic room had a higher adjusted $\mathrm{HR}$ for hip fracture $(\mathrm{HR}=$ $4.55,95 \%$ CI, 2.69-7.70).

\section{Discussion}

This study examined the relationship between type of LTC services and incidence of hip fracture among elderly with LTCI benefit coverage level 1 or 2 with dementia using nationwide elderly cohort data. According to the results controlling for potential confounders, IC was found to be associated with a higher incidence of hip fracture compared to $\mathrm{HC}$. In particular, the association between type to LTC services and the incidence of hip fracture was especially high among IC beneficiaries who were female, lived in rural areas, had no predetermined risk of fracture based on the mandatory assessment for LTC benefits, and who were partially able or unable to ambulate.

In comparison with previous studies, there is a one study examined the association between type of LTC and incidence of pressure ulcer in Korean elderly patients with dementia; although that study used development of pressure ulcers instead of hip fracture as a quality indicator in LTC, the results are comparable to our study and found that beneficiaries with IC were more likely to be associated with the incidence of pressure ulcers compared to those with HC [18]. Another study tested whether the type of LTC services is associated with cognitive function, physical functioning, behavioral symptoms. In that study, IC users were associated with poor cognitive function, poor physical functioning, and better behavioral symptoms compared with those receiving $\mathrm{HC}$ services [13].

In this study, older adults with IC services were found more likely to be associated with the incidence of hip fracture than $\mathrm{HC}$ users, and this result can be explained by the different care environment. Older adults receiving $\mathrm{HC}$ services are able to obtain care from their family caregiver when any LTC worker is not around. On the other hand, those who receive IC services live in a LTC institution for $24 \mathrm{~h}$, and they are in a situation in which they have to fully depend of LTC workers for every care need [19]. To prevent hip fracture, proper care and supervision from a daily caregiver is important. Also, living in an environment with the use of protective equipment to prevent hip fracture is important [12], and providing this environment is one role of LTC services. A previous study found that fall-related knowledge 
Table 1 Baseline Characteristics by Incidence of Hip Fracture

\begin{tabular}{|c|c|c|c|c|c|c|c|}
\hline \multirow[t]{2}{*}{ Variable } & \multirow[t]{2}{*}{$\mathrm{N}$} & \multirow{2}{*}{$\begin{array}{l}\text { Col } \\
\%^{a}\end{array}$} & \multicolumn{2}{|c|}{ No Hip Fracture } & \multicolumn{2}{|c|}{ Hip Fracture } & \multirow{3}{*}{$\begin{array}{l}\text { P- } \\
\text { value }\end{array}$} \\
\hline & & & $\bar{N}$ & Row $\%^{\mathrm{b}}$ & $\bar{N}$ & Row $\%^{b}$ & \\
\hline Total & 7112 & 100.0 & 6997 & 98.4 & 115 & 1.6 & \\
\hline \multicolumn{8}{|l|}{ Type of care } \\
\hline Institutional care & 2802 & 39.4 & 2712 & 96.8 & 90 & 3.2 & \multirow[t]{2}{*}{$<.0001$} \\
\hline Home care & 4310 & 60.6 & 4285 & 99.4 & 25 & 0.6 & \\
\hline \multicolumn{8}{|l|}{ Age } \\
\hline $60-74$ & 1131 & 15.9 & 1117 & 98.8 & 14 & 1.2 & \multirow[t]{5}{*}{0.380} \\
\hline $75-80$ & 1795 & 25.2 & 1769 & 98.6 & 26 & 1.5 & \\
\hline $81-85$ & 1810 & 25.5 & 1782 & 98.5 & 28 & 1.6 & \\
\hline $86-90$ & 1454 & 20.4 & 1428 & 98.2 & 26 & 1.8 & \\
\hline $91 \leq$ & 922 & 13.0 & 901 & 97.7 & 21 & 2.3 & \\
\hline \multicolumn{8}{|l|}{ Sex } \\
\hline Male & 1963 & 27.6 & 1951 & 99.4 & 12 & 0.6 & \multirow[t]{2}{*}{$<.0001$} \\
\hline Female & 5149 & 72.4 & 5046 & 98.0 & 103 & 2.0 & \\
\hline \multicolumn{8}{|l|}{ Region } \\
\hline Urban & 2835 & 39.9 & 2791 & 98.5 & 44 & 1.6 & \multirow[t]{2}{*}{0.724} \\
\hline Rural & 4277 & 60.1 & 4206 & 98.3 & 71 & 1.7 & \\
\hline \multicolumn{8}{|l|}{ Income level } \\
\hline Low & 2565 & 36.1 & 2515 & 98.1 & 50 & 2.0 & \multirow[t]{3}{*}{0.170} \\
\hline Middle & 1173 & 16.5 & 1153 & 98.3 & 20 & 1.7 & \\
\hline High & 3374 & 47.4 & 3329 & 98.7 & 45 & 1.3 & \\
\hline \multicolumn{8}{|l|}{ Primary Caregiver } \\
\hline Spouse & 1277 & 18.0 & 1271 & 99.5 & 6 & 0.5 & \multirow[t]{4}{*}{$<.0001$} \\
\hline Children & 3285 & 46.2 & 3243 & 98.7 & 42 & 1.3 & \\
\hline Care assistant & 2341 & 32.9 & 2280 & 97.4 & 61 & 2.6 & \\
\hline None & 209 & 2.9 & 203 & 97.1 & 6 & 2.9 & \\
\hline \multicolumn{8}{|l|}{ Cohabitant } \\
\hline Living alone & 360 & 5.1 & 358 & 99.4 & 2 & 0.6 & \multirow[t]{5}{*}{$<.0001$} \\
\hline Spouse (one generation family) & 1096 & 15.4 & 1088 & 99.3 & 8 & 0.7 & \\
\hline Family members (two generation family) & 3127 & 44.0 & 3083 & 98.6 & 44 & 1.4 & \\
\hline Caregivers from Long term care facilities & 1593 & 22.4 & 1548 & 97.2 & 45 & 2.8 & \\
\hline Others & 936 & 13.2 & 920 & 98.3 & 16 & 1.7 & \\
\hline \multicolumn{8}{|c|}{ Having danger of fracture based on the mandatory assessment for long term care benefit ${ }^{c}$} \\
\hline Yes & 5457 & 76.7 & 5379 & 98.6 & 78 & 1.4 & \multirow[t]{2}{*}{0.023} \\
\hline No & 1655 & 23.3 & 1618 & 97.8 & 37 & 2.2 & \\
\hline \multicolumn{8}{|l|}{ LTCI benefit coverage level } \\
\hline 1 & 183 & 2.6 & 179 & 97.8 & 4 & 2.2 & 0.537 \\
\hline 2 & 6929 & 97.4 & 6818 & 98.4 & 111 & 1.6 & \\
\hline Charlson Comorbidity Index (CCl) & & & & & & & \\
\hline 0 & 1655 & 23.3 & 1630 & 98.5 & 25 & 1.5 & 0.738 \\
\hline 1 & 2167 & 30.5 & 2136 & 98.6 & 31 & 1.4 & \\
\hline 2 & 1540 & 21.7 & 1513 & 98.3 & 27 & 1.8 & \\
\hline $3+$ & 1750 & 24.6 & 1718 & 98.2 & 32 & 1.8 & \\
\hline LTC approval score (LTCAS, mean \pm SD) & & & $81.5 \pm$ & & $83.8=$ & & \\
\hline
\end{tabular}


Table 1 Baseline Characteristics by Incidence of Hip Fracture (Continued)

\begin{tabular}{|c|c|c|c|c|c|c|c|}
\hline \multirow[t]{2}{*}{ Variable } & \multirow[t]{2}{*}{$\mathrm{N}$} & \multirow{2}{*}{$\begin{array}{l}\text { Col } \\
\%^{\mathrm{a}}\end{array}$} & \multicolumn{2}{|c|}{ No Hip Fracture } & \multicolumn{2}{|c|}{ Hip Fracture } & \multirow{3}{*}{$\begin{array}{l}\text { P- } \\
\text { value }\end{array}$} \\
\hline & & & $\bar{N}$ & Row $\%{ }^{b}$ & $\bar{N}$ & Row \% ${ }^{b}$ & \\
\hline Total & 7112 & 100.0 & 6997 & 98.4 & 115 & 1.6 & \\
\hline $\mathrm{ADL}($ mean $\pm \mathrm{SD})$ & & & \multicolumn{2}{|l|}{$32.3 \pm 4.1$} & \multicolumn{2}{|c|}{$33.6 \pm 5.2$} & \\
\hline Cognitive function score (mean \pm SD) & & & \multicolumn{2}{|l|}{$7.0 \pm 2.1$} & \multicolumn{2}{|c|}{$7.0 \pm 1.9$} & \\
\hline Behavioral symptoms score (mean \pm SD) & & & \multicolumn{2}{|l|}{$3.6 \pm 3.2$} & \multicolumn{2}{|c|}{$3.3 \pm 3.1$} & \\
\hline \multicolumn{8}{|l|}{ Ambulatory status } \\
\hline Ambulatory & 1243 & 17.5 & 1225 & 98.6 & 18 & 1.5 & \multirow[t]{3}{*}{0.003} \\
\hline Partially ambulatory & 2800 & 39.4 & 2770 & 98.9 & 30 & 1.1 & \\
\hline Not ambulatory & 3069 & 43.2 & 3002 & 97.8 & 67 & 2.2 & \\
\hline \multicolumn{8}{|l|}{ Ownership type } \\
\hline Local government & 277 & 3.9 & 269 & 97.1 & 8 & 2.9 & \multirow[t]{3}{*}{0.077} \\
\hline Non-profit & 2836 & 39.9 & 2784 & 98.2 & 52 & 1.8 & \\
\hline Private & 3999 & 56.2 & 3944 & 98.6 & 55 & 1.4 & \\
\hline
\end{tabular}

${ }^{a}$ It presented column percentage. Column percentage shows the proportion of a total of 7112 participants in each category

${ }^{b}$ It presented row percentage. Row percentage add up to each row total, and shows the proportion within each characteristics in each row by whether having the incidence of hip fracture or not

'The record regarding having pressure ulcer was based on the information of patients' mandatory assessment data, which is requested to qualify to become a long-term care beneficiaries

among nursing home workers is not adequate to prevent accidental falls, and therefore, re-education is needed for fall prevention [20]. Also, previous studies have shown that patients who live with family members who know how to prevent hip fracture have a lower risk of fall [21].
The finding of this study shows that although patients in institutional care facilities are fully dependent on LTC workers, these workers are providing inadequate preventive care for hip fractures. Another previous study showed that elderly adults in institutional care tend to

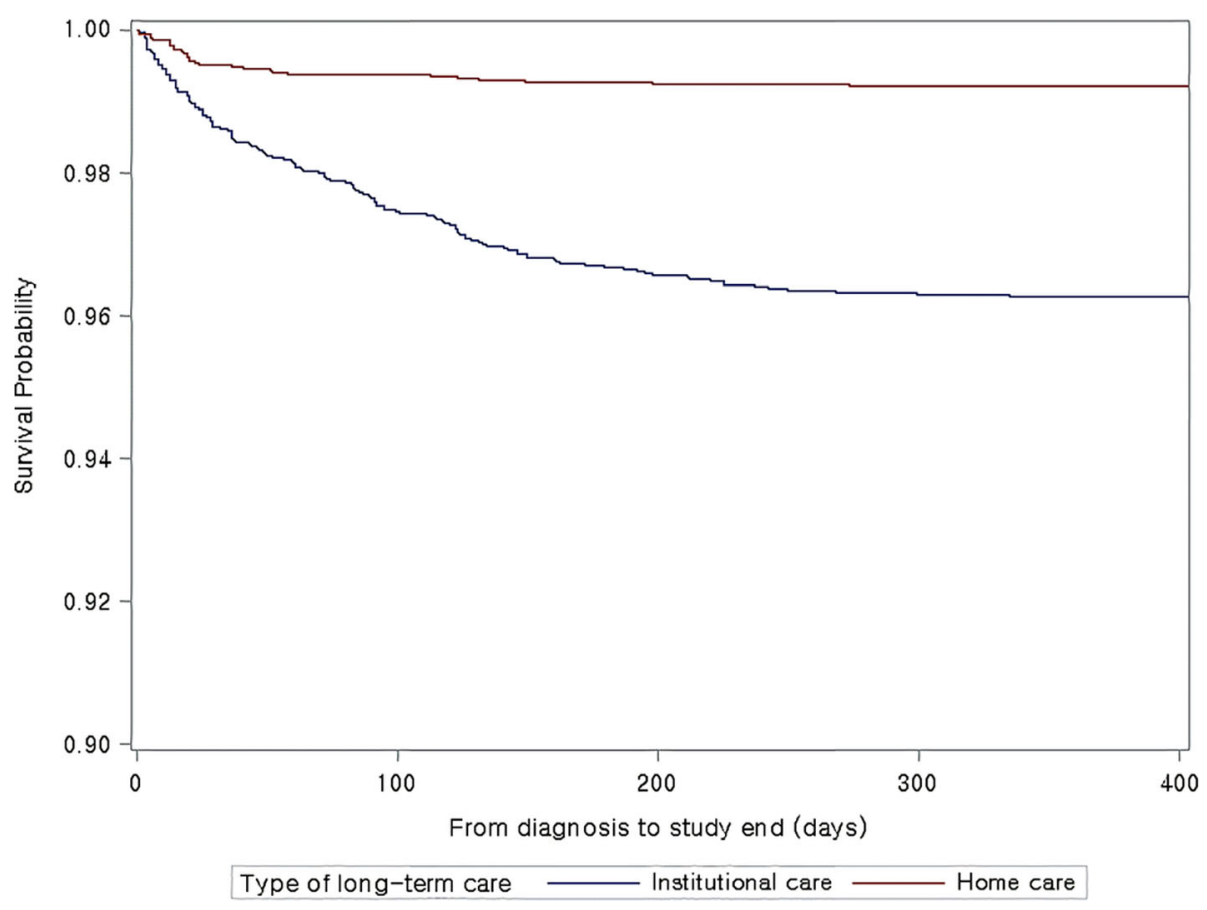

Fig. 1 The mean survival time of those with home care and institutional care was 325.5 days and 271.3 days, respectively. The difference in survival for the incidence of hip fracture in participants was greatest at 400 days ( $p$-value $<0.0001$ by log-rank test). The survival probability for the incidence of hip fracture in those older adults with $\mathrm{IC}$ is more likely to rapidly decrease over time than the survival probability of those older adults with $\mathrm{HC}$ 
Table 2 Adjusted hazard ratios for factors associated with hip fracture

\begin{tabular}{|c|c|c|c|}
\hline \multirow{3}{*}{$\begin{array}{l}\text { Variable } \\
\text { Total } \\
\text { Type of care }\end{array}$} & \multicolumn{3}{|c|}{ Hip fracture } \\
\hline & \multirow[t]{2}{*}{$\mathrm{HR}^{\mathrm{b}}$} & \multicolumn{2}{|c|}{$95 \% \mathrm{Cl}$} \\
\hline & & & \\
\hline Institutional care & 4.32 & 2.83 & 6.58 \\
\hline Home care & 1.00 & & \\
\hline \multicolumn{4}{|l|}{ Age } \\
\hline $60-74$ & 1.00 & & \\
\hline $75-80$ & 1.18 & 0.71 & 1.95 \\
\hline $81-85$ & 1.30 & 0.78 & 2.16 \\
\hline $86-90$ & 1.40 & 0.82 & 2.37 \\
\hline $91 \leq$ & 2.30 & 1.33 & 3.98 \\
\hline \multicolumn{4}{|l|}{ Sex } \\
\hline Male & 0.79 & 0.51 & 1.23 \\
\hline Female & 1.00 & & \\
\hline \multicolumn{4}{|l|}{ Region } \\
\hline Urban & 1.16 & 0.86 & 1.57 \\
\hline Rural & 1.00 & & \\
\hline \multicolumn{4}{|l|}{ Income level } \\
\hline Low & 1.00 & & \\
\hline Middle & 0.90 & 0.57 & 1.41 \\
\hline High & 0.95 & 0.69 & 1.31 \\
\hline \multicolumn{4}{|l|}{ Primary Caregiver } \\
\hline Spouse & 0.21 & 0.07 & 0.67 \\
\hline Children & 0.47 & 0.23 & 0.96 \\
\hline Care assistant & 1.00 & & \\
\hline None & 0.34 & 0.18 & 0.65 \\
\hline \multicolumn{4}{|l|}{ Cohabitant } \\
\hline Living alone & 1.00 & & \\
\hline Spouse (one generation family) & 2.54 & 0.73 & 8.90 \\
\hline Family members (two generation family) & 2.16 & 0.83 & 5.63 \\
\hline Caregivers from Long term care facilities & 2.98 & 1.17 & 7.60 \\
\hline Others & 1.53 & 0.57 & 4.09 \\
\hline
\end{tabular}

Having danger of fracture based on the mandatory assessment for long term care benefit ${ }^{a}$

Yes

No

LTCI benefit coverage level

$$
1
$$$$
2
$$

Charlson Comorbidity Index (CCI)

$$
\begin{aligned}
& 0 \\
& 1
\end{aligned}
$$$$
2
$$$$
3+
$$

LTC approval score (LTCAS, mean \pm SD)
1.00

1.28

0.91

1.80

0.44

0.15

1.32

1.00

1.00

1.02

0.67

1.37

0.88

1.56

1.86

1.21

2.15

1.00
Table 2 Adjusted hazard ratios for factors associated with hip fracture (Continued)

\begin{tabular}{llll}
\hline Variable & \multicolumn{3}{l}{ Hip fracture } \\
\cline { 2 - 4 } Total & $\mathrm{HR}^{\mathrm{b}}$ & $95 \% \mathrm{Cl}$ & \\
\hline ADL (mean $\pm \mathrm{SD}$ ) & 1.04 & 0.99 & 1.09 \\
Cognitive function score (mean $\pm \mathrm{SD})$ & 0.98 & 0.91 & 1.05 \\
Behavioral symptoms score (mean $\pm \mathrm{SD})$ & 0.92 & 0.86 & 0.98 \\
Ambulatory status & & & \\
$\quad$ Ambulatory & 1.00 & & \\
$\quad$ Partially ambulatory & 1.12 & 0.67 & 1.87 \\
$\quad$ Not ambulatory & 1.96 & 1.19 & 3.22 \\
Ownership type & & & \\
$\quad$ Local government & 1.00 & & \\
$\quad$ Non-profit & 0.72 & 0.42 & 1.26 \\
$\quad$ Private & 0.73 & 0.41 & 1.29 \\
\hline
\end{tabular}

The record regarding having danger of fracture was based on the information of patients' mandatory assessment data, which is requested to qualify to become long-term care beneficiaries

${ }^{b}$ Adjusted for age, sex, region, income level, primary caregiver, cohabitant, having danger of fracture based on the mandatory assessment for long-term care benefit, LTCI benefit coverage level, CCI, LTCAS, ADL, cognitive function score, ambulatory status, and ownership type

Table 3 Result of subgroup analysis regarding the association

\begin{tabular}{|c|c|c|c|c|c|}
\hline \multirow{3}{*}{$\begin{array}{l}\text { Variable } \\
\text { Total }\end{array}$} & \multicolumn{5}{|c|}{ Type of care } \\
\hline & \multicolumn{3}{|c|}{ Institutional care } & \multicolumn{2}{|c|}{ Home care } \\
\hline & $H R^{b}$ & $95 \%$ & & $\overline{H R^{b}}$ & $95 \% \mathrm{Cl}$ \\
\hline \multicolumn{6}{|l|}{ Sex } \\
\hline Male & 3.54 & 1.24 & 10.09 & 1.00 & \\
\hline Female & 4.73 & 2.96 & 7.53 & 1.00 & \\
\hline \multicolumn{6}{|l|}{ Region } \\
\hline Urban & 4.26 & 2.27 & 7.90 & 1.00 & \\
\hline Rural & 4.69 & 2.60 & 8.44 & 1.00 & \\
\hline
\end{tabular}
between type of care and the incidence of hip fracture by factors

Having danger of fracture based on the mandatory assessment for long term care benefit ${ }^{\mathrm{a}}$

$\begin{array}{lllll}\text { Yes } & 4.09 & 2.53 & 6.62 & 1.00 \\ \text { No } & 5.27 & 2.15 & 12.92 & 1.00\end{array}$

Ambulatory status

$\begin{array}{lllll}\text { Ambulatory } & 2.21 & 0.61 & 8.02 & 1.00 \\ \text { Partially ambulatory } & 4.96 & 2.24 & 11.00 & 1.00 \\ \text { Not ambulatory } & 4.62 & 2.69 & 7.94 & 1.00\end{array}$

${ }^{2}$ The record regarding having danger of fracture was based on the information of patients' mandatory assessment data, which is requested to qualify to become long-term care beneficiaries

${ }^{\mathrm{b}}$ Adjusted for age, sex, region, income level, primary caregiver, cohabitant, having danger of fracture based on the mandatory assessment for long-term care benefit, LTCI benefit coverage level, CCI, LTCAS, ADL, cognitive function score, ambulatory status, and ownership type 
Table 4 Adjusted hazard ratios regarding the association between structural characteristics of institution and incidence of hip fracture among beneficiaries with institutional care

\begin{tabular}{lllll}
\hline Variable & \multicolumn{3}{l}{ Hip fracture } \\
\cline { 3 - 5 } & & $\mathrm{HR}^{\mathrm{a}}$ & $95 \% \mathrm{Cl}$ & \\
\hline Number of clinic room & & & & \\
Home care & & & & \\
Institutional care & without clinic room & 4.55 & 2.69 & 7.70 \\
& with clinic room & 4.26 & 2.77 & 6.57
\end{tabular}

${ }^{a}$ Adjusted for age, sex, region, income level, primary caregiver, cohabitant, having danger of fracture based on the mandatory assessment for long-term care benefit, LTCl benefit coverage level, CCI, LTCAS, ADL, cognitive function score, ambulatory status, and ownership type

have poorer health than those who receive home care [22]. For these reasons, beneficiaries who receive institutional care may be at a higher risk for hip fracture.

In the subgroup analysis by region, the effect of receiving institutional care on the incidence of hip fracture was larger among those who lived in rural areas compared to urban areas. This can be explained by the regional inequality of care services and different characteristics between urban and rural residences. Previous studies have reported that rural nursing home facilities were associated with poorer quality of care [23]. Also, rural residents were more likely to be older and poor, with a worse health status, and less likely to receive preventive services and visit health care providers [24].

In the subgroup analysis by gender, the effect of receiving institutional care on the risk of hip fracture was greater among females than males. A previous study found that older female adults were more vulnerable to falls [25]; therefore, older female adults should receive more focused care to prevent falls. The results of the present study suggest that proper care was not fully provided from LTC workers to older female adults, who are more likely to have fall injuries.

The subgroup analysis indicated that incidence of hip fracture was particularly high among beneficiaries who had no predetermined risk of fracture during their mandatory assessment for benefit eligibility. Proper care and a living environment that prevents falls in daily life are essential for reducing fall injuries including hip fracture among all elderly people, considering their frailty and low mobility [12]. However, LTC workers are likely to focus their daily attention on patients with a known a predetermined risk of fracture, rather than those with no known risk. This naturally deprioritizes preventative care of hip fracture for beneficiaries without a predetermined risk of fracture based on the mandatory assessment. Similar reasoning might explain why the risk of hip fracture was particularly high among those who were not only non-ambulatory but also partially ambulatory: those who are not ambulatory are a high-risk population, and thus receive focused care for preventing hip fracture, whereas those who are ambulatory have a low risk of hip fracture.

This study has several strengths. To the best of our knowledge, this is the first study to examine the associations between type of LTC services and incidence of hip fracture based on nationally representative sample.

This study has some limitations as well. Firstly, the incidence of hip fracture could be underestimated. Medical practitioners could under-report the incidence of hip fracture on medical records to report better quality indicator of LTC services. Second, the reason for higher incidence of hip fracture among older persons living in facility could be due to a longer distance to fulfill daily activities (e.g., from bedroom to bathroom or to living room) but the factors regarding this issue such as average walking time or the way of living was not able to consider in this study due to data constraint. In addition, the observational nature of our study leaves room for residual confounding and other potential sources of bias.

This study has several implications. First, the government need to watch the institutional LTC services quality and promote improvements of the IC services quality. To promote IC services quality improvement, payments system to LTC providers should be reformed to encourage LTC provider to improve services quality. For example, the results of service quality assessment in the process of payment. Second, LTC workers should be careful not to disregard preventative care of hip fracture for those older adults without a predetermined risk of fracture during mandatory assessment for benefit eligibility, who are unable to ambulate and who are partially ambulatory, and who are female. Finally, efforts are needed to increase LTC service quality for beneficiaries living in rural area. Since the introduction of LTC in 2008, efforts to increase the quantity of long-term care across Korea have been made, but efforts to alleviate the differences in quality of LTC services between urban and rural areas have been inadequate. Considering that large number of older people live in rural areas, efforts should be made to eliminate regional differences in quality of LTC services.

\section{Conclusion}

LTC beneficiaries who receive institutional care had higher adjusted HRs of hip fracture than did those who received home care. The government should monitor and promote LTC service providers to improve the quality of IC.

\section{Abbreviations}

ADL: Activities of daily living; CCl: Charlson Comorbidity Index; HC: Home care; HR: Hazards ratio; IADL: Instrumental ADLs; IC: Institutional care; ICD10: International Classification of Diseases, Tenth Edition; LTC: Long-term 
care; LTCAC: LTC checklist; LTCAS: LTC approval scores; LTCI: Long-term care insurance

\section{Acknowledgments}

Not applicable.

\section{Authors' contributions}

JYK designed the study, performed statistical analyses, and wrote the manuscript. ECP contributed to the discussion and reviewed the manuscript. YC contributed to check the accuracy of the data analysis and designed the study. All authors read and approved the final manuscript.

\section{Funding}

This research did not receive any specific grant from funding agencies in the public, commercial, or not-for-profit sectors.

\section{Availability of data and materials}

Researchers interested in using Korean Elderly Cohort data may access the data from the following sites: https://nhiss.nhis.or.kr/bd/ab/bdabd003cv.do. The authors do not have the legal right to distribute or provide access to the data set.

\section{Ethics approval and consent to participate}

This study was approved by the Institutional Review Board of Yonsei University School of Public Health, Seoul, Korea [IRB number 2-1040939-AB$\mathrm{N}-01-2016-155]$. The data used in this study are completely anonymous and does not include any personal information related to the participants, so this study did not require informed consent from the patients.

\section{Consent for publication}

The authors declare that they have no competing interests.

\section{Competing interests}

The authors declare that they have no competing interests.

\section{Author details}

${ }^{1}$ Department of Health \& Human Performance, Sahmyook University, Seoul, Republic of Korea. ${ }^{2}$ Department of Biomedical Informatics, Ajou University School of Medicine, Suwon, Gyeonggi-do, Republic of Korea. ${ }^{3}$ Institute of Health Services Research, Yonsei University, Seoul, Republic of Korea.

${ }^{4}$ Department of Preventive Medicine \& Institute of Health Services Research, Yonsei University College of Medicine, 50 Yonsei-ro, Seodaemun-gu, Seoul 120-752, Republic of Korea.

Received: 11 January 2018 Accepted: 17 May 2019

Published online: 28 May 2019

\section{References}

1. Lee S. Dementia strategy Korea. Int J Geriatr Psychiatry. 2010;25(9):931-2.

2. Kwon S. Future of long-term care financing for the elderly in Korea. J Aging Soc Policy. 2008;20(1):119-36

3. Kwon S. The introduction of long-term care insurance in South Korea. Eurohealth. 2009;15(1):28

4. Kim S, Kim D, Kim W. Long-term care needs of the elderly in Korea and elderly long-term care insurance. Soc Work Public Health. 2010;25(2):176-84.

5. Lee MK, Kim EK. Relationship between resource utilization and long-term care classification level for residents in nursing homes. J Korean Acad Nurs. 2010;40(6):903-12.

6. Long-term care insurance statistical yearbook. 2016. http://www.nhis.or.kr/ bbs7/boards/B0160/24105?boardKey=37\&sort=sequence\&order= desc\&rows=10\&messageCategoryKey=\&pageNumber=1\&viewType $=$ generic\&targetType=12\&targetKey $=37 \&$ status $=\&$ period $=\&$ startdt $=\&$ enddt $=$ \&queryField=\&query $=$.

7. Future of family medicine project leadership committee: future strategies for advancement of health care insurance. 2004.

8. Wagner $\mathrm{C}$, Ikkink KK, van der Wal G, Spreeuwenberg P, de Bakker DH, Groenewegen PP. Quality management systems and clinical outcomes in Dutch nursing homes. Health Policy. 2006;75(2):230-40.

9. Lee TW, Cho E, Ko YK, Whang Y, Kim BN, Lim ES, et al. Development of the quality indicators in long term care service. J Korean Acad Nurs. 2012;18(1): 106-17.
10. Lu-Yao GL, Baron JA, Barrett JA, Fisher ES. Treatment and survival among elderly Americans with hip fractures: a population-based study. Am J Public Health. 1994;84(8):1287-91.

11. Johansson C, Skoog I. A population-based study on the association between dementia and hip fractures in 85-year olds. Aging (Milan, Italy). 1996:8(3):189-96.

12. Rubenstein LZ. Falls in older people: epidemiology, risk factors and strategies for prevention. Age Ageing. 2006;35(suppl 2):ii37-41.

13. Lee TW, Yim E, Cho E, Chung J. Cognitive function, behavioral problems, and physical function in long-term care insurance beneficiaries with dementia in South Korea: comparison of home care and institutional care services. J Am Geriatr Soc. 2014;62(8):1467-75.

14. Seok JE. Public long-term care insurance for the elderly in Korea: design, characteristics, and tasks. Soc Work Public Health. 2010;25(2):185-209.

15. Lipscombe LL, Jamal SA, Booth GL, Hawker GA. The risk of hip fractures in older individuals with diabetes. Diabetes Care. 2007;30(4):835-41.

16. Charlson ME, Pompei $P$, Ales KL, MacKenzie CR. A new method of classifying prognostic comorbidity in longitudinal studies: development and validation. J Chronic Dis. 1987;40(5):373-83.

17. Nelson WB. Recurrent events data analysis for product repairs, disease recurrences, and other applications, vol. 10. Philadelphia: SIAM; 2003.

18. Kim J, Choi Y, Shin J, Jang SY, Cho KH, Nam JY, Park EC. Incidence of pressure ulcers during home and institutional care among long-term care insurance beneficiaries with dementia using the Korean elderly cohort. Am Med Dir Assoc. 2017;18(7):638-e1.

19. Williams SW, Zimmerman S, Williams CS. Family caregiver involvement for long-term care residents at the end of life. J Gerontol B Psychol Sci Soc Sci. 2012;67(5):595-604.

20. Kim MS, Eun Y. Fall-related knowledge and caring behaviors for fall prevention among care workers in nursing home. J Muscle Joint Health. 2014:21(1):11-8.

21. Potter $P$, Olsen $S$, Kuhrik M, Kuhrik N, Huntley LR. A DVD program on fall prevention skills training for cancer family caregivers. J Cancer Educ. 2012; 27(1):83-90

22. Park CJ. Determinants of long term care service types of family caregiver. J Welfare Aged. 2015;70(1):31-51

23. Kang $Y$, Meng $H$, Miller NA. Rurality and nursing home quality: evidence from the 2004 National Nursing Home Survey. Gerontologist. 2011;51(6): 761-73.

24. Agency for Healthcare Research and Quality: National Health Disparties Report. 2013; [https://archive.ahrq.gov/research/findings/nhqrdr/nhdr13/ 2013nhdr.pdf].

25. Chu L-W, Chi I, Chiu A. Incidence and predictors of falls in the Chinese elderly. Ann Acad Med Singap. 2005:34(1):60-72.

\section{Publisher's Note}

Springer Nature remains neutral with regard to jurisdictional claims in published maps and institutional affiliations.

Ready to submit your research? Choose BMC and benefit from:

- fast, convenient online submission

- thorough peer review by experienced researchers in your field

- rapid publication on acceptance

- support for research data, including large and complex data types

- gold Open Access which fosters wider collaboration and increased citations

- maximum visibility for your research: over $100 \mathrm{M}$ website views per year

At $\mathrm{BMC}$, research is always in progress.

Learn more biomedcentral.com/submissions 